\title{
ASSESSMENT OF ANTIMICROBIAL AND ANTIOXIDANT ACTIVITIES OF AMOMUM SUBULATUM ROXB. OF NEPAL
}

\author{
BIMALA SUBBA ${ }^{1 *}$, TANK RAJ SELING ${ }^{1}$, RAM CHANDRA KANDEL ${ }^{2}$, GANGA PRASAD PHUYAL ${ }^{3}$ \\ ${ }^{1}$ Department of Chemistry, Tribhuvan University, Kirtipur, Kathmandu, Nepal. ${ }^{2}$ Department of Biochemistry, Universal Science College, \\ Chakupat, Lalitpur, Nepal. ${ }^{3}$ Department of Chemistry, Trichandra Multiple Campus, Ghantaghar, Kathmandu, Nepal.
} Email: bimalasubba@gmail.com

Received: 03 November 2017, Revised and Accepted: 04 January 2017

ABSTRACT

Objective: The present study was designed to study and compare the antibacterial and antioxidant activity of methanol extracts of Amomum subulatum Roxb. seeds collected from two different regions of Nepal.

Methods: Antioxidant activity was determined by 1, 1-diphenyl-2-picrylhydrazyl assay and Antibacterial activity was measured by agar well-diffusion method.

Results: Results showed that both sample extracts had interesting antibacterial activity against all test microorganisms and had remarkable radical scavenging potential to be used as an antioxidant. Sample B (i.e., collected from high altitude Taplejung district) exerted comparative quit higher antimicrobial and antioxidant activity than the Sample A (i.e., is collected from low altitude Panchthar district). However, the standard antibacterial drug Tetracycline exhibits superior activity than the extracts.

Conclusions: The results suggest that both samples (i.e., seed extract of $A$. subulatum Roxb.) possess almost similar moderate antibacterial and antioxidant activity in comparison to standards which justifies the traditional use of this plant.

Keywords: Extract, Cardamom, Activity, Medicinal plants, Seeds, Bacillus pumilus.

(C) 2017 The Authors. Published by Innovare Academic Sciences Pvt Ltd. This is an open access article under the CC BY license (http://creativecommons. org/licenses/by/4. 0/) DOI: http://dx.doi.org/10.22159/ajpcr.2017.v10i4.16018

\section{INTRODUCTION}

Cardamom (Amomum subulatum Roxb.) is a genus of terrestrial, rhizomatous herb, distributed chiefly Nepal and India, found in the Northern West Bengal, Sikkim, Assam hills and cultivated in Nepal [1]. Cardamom is valuable spice that is obtained from the seeds of a perennial plant Elettaria cardamom. Cardamom originated from the coastal area of India. It is now grow in Nepal, Tanzania, Vietnam, Laos, Sri Lanka, and Bhutan [2]. There are two main types of cardamom: (a) Small green cardamom (E. cardamom) and (b) Large red/black cardamom (A. subulatum). The most common type is the small green cardamom while large cardamom is mainly grown in India, Nepal, and Bhutan. They both come from Zingiberaceae family of plants [3].

The black cardamom (A. subulatum) bush grows to a height of about $3 \mathrm{~m}$. It grows best in a warm humid place where there is plenty of rain and rich soil. It can grow at altitude up to $1370 \mathrm{~m}$ above sea level. The bush requires shade and is usually grow under natural forest cover. The tree produces flowers after it is 2-3 years old [4]. The first crop of seed capsule is harvested in the $3^{\text {rd }}$ year after planting. Harvesting at the correct stage of maturity is essential to produce high-quality cardamom capsules. The fruits should be harvested once they are fully ripe and mature. A ripe capsule has black seeds inside. An immature capsule has white seeds. Drying is the most important part of the process as it affects the quality; thus, the crop should be cleaned before the drying of the final product. It is important to dry the cardamom capsules as soon after harvest as possible to prevent the loss of flavor. The drying temperature should not above $50^{\circ} \mathrm{C}$ as this affects the color and delicate flavor of final product. There are several options available to the small scale processor, depending on the size of the business and the local weather conditions at the time of processing. They are (a) sun drying, (b) solar drying, (c) wood-fired dryer, and (d) electric or gas dryer. In Nepal and India, cardamom capsules are traditionally dried in caring houses, using wood to provide the heat. Cardamom graded by color and size. The deeper the green color and the larger the capsule size, the higher the grade. All grading is done manually [5].

The seeds are reported to poses stimulant, stomachic, alexipharmic, and astringent properties and are used in folklore medicine for the treatment of indigestion, vomiting, biliousness, abdominal pains, and rectal diseases [6]. The seeds are found to promote elimination of bile and are used to treat congestive jaundice and headache; they are also used in gonorrhea. It is one of the ingredients used to make Nepali Garam masala spice blends and is also used in meat curries, sweet seeds, rice dishes, and pickles. It has sweet seeds and smoky fragrance [7].

A. subulatum is largely produced in the organic way in cultivated farms throughout Nepal. The most popular framing areas of Himalayan range are Taplejung, Panchthar, Sankhuwasabha, Ilam, Tehrathum, and Dhankuta district in Nepal. It is one of the important cash crops for the Nepali framers to celebrate especially great festival Dashain and Tihar, as ripen black cardamom is usually harvest from mid-August to November to earn money. Natural antioxidants, especially phenolic and flavonoids, have biological activity as well as safety, for human being; therefore, most studies are on antioxidants of plant origin [8-11]. High-altitude medicinal plants had been the first choice of local users as immediate therapy and by pharmaceutical companies as precious ingredients as they provide quality products $[12,13]$. Despite black cardamom is high-value cash crop with biological activity, scientifically its evaluations have not been studied so far. Thus, here, we carried out the comparative analysis of two samples of A. subulatum: One is collected from high altitude Taplejung district and other from low altitude Panchthar district of Nepal.

A. subulatum fruits were collected by Tank Raj Seling from his hometown of Panchthar (Himalayan range) that was assigned as Sample A and 
other sample from Taplejung district, which is located at high altitude than Panchthar district of Nepal and assigned as Sample B. Fruits of both samples were further dried in oven at $60^{\circ} \mathrm{C}$ and peeled off to collect about $150 \mathrm{~g}$ seed of each sample. Extraction was carried out by soaking $150 \mathrm{~g}$ of dried powdered samples in about $600 \mathrm{ml}$ of methanol (Analar grade) for 3 days. The extract was concentrated under reduced pressure using a rotary evaporator and then stored in an airtight container for further study. The plant was identified with the help of available literature and authenticated by the taxonomist at Central Department of Botany, Tribhuvan University, Kirtipur, Kathmandu, Nepal.

The chemicals used were methanol (Merck, Germany), 1-diphenyl-2picrylhydrazyl (DPPH), and ascorbic acid (Sigma Aldrich, USA). Mueller Hinton agar medium for antibacterial activity was purchased from Himedia, India. All other chemicals used were of the highest commercially available grade. For absorption measurement, double beam U-2800 ultraviolet (UV)-visible spectrometer, HITACHI, Japan, was used.

The antibacterial assay of seed extracts was carried using Agar well diffusion method based on the procedure given by Dingle et al. [14]. The wells were made in the incubated media plates with the help of sterile Cork borer $(6 \mathrm{~mm})$ and labeled properly.

Solutions of known concentration $(0.1 \mathrm{mg} / \mathrm{mL})$ of the test samples were made by dissolving measured amount of the samples in calculated volume of solvents. Then, $50 \mu \mathrm{l}$ of the working solution of the extract was loaded into the respective wells with the help of micropipette. The solvent dimethyl sulfoxide (DMSO+water) was tested for its activity as a control at the same time in the separate well. The plates were then left for $1 / 2 \mathrm{hr}$ with the lid closed so that extracts diffused to the media. The plates were incubated overnight at $37^{\circ} \mathrm{C}$.

After incubation, the growth inhibition rings were quantified by measuring the diameter of the zone of inhibition in $\mathrm{mm}$. A broadspectrum antibiotic tetracycline $(10 \mathrm{mg} / \mathrm{ml})$ was used as a positive control and DMSO $(50 \mu \mathrm{l})$ as a negative control. All tests were performed in triplicate. The microorganisms used in this study were identified strains obtained from the Central Department of Microbiology, Tribhuvan University, Nepal. Among the bacteria taken in this study, two were Gram-positive and two were Gram-positive.

Gram-positive - Bacillus pumilus, Staphylococcus aureus.

Gram-negative - Escherichia coli, Salmonella enteric.

The DPPH assay was performed following standard protocol $[15,16]$. The plant samples at various concentrations $(100-1000 \mu \mathrm{g} / \mathrm{ml})$ were added to a $100 \mu \mathrm{M}$ solution of DPPH in methanol. The mixture was allowed to stand for 30 minutes to perform complete reaction in dark. Then, absorbance was measured at $517 \mathrm{~nm}$ using UV spectrophotometer; radical scavenging activity of each sample was calculated using following formula.
Radical scavenging activity $(\%)=\left(\mathrm{A}_{\mathrm{o}}-\mathrm{A}_{\mathrm{s}} / \mathrm{A}_{\mathrm{o}}\right) \times 100$

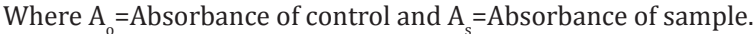

Control was the test solution without sample. $\mathrm{IC}_{50}$ is defined as the amount of antioxidant required to inhibit 50\% of DPPH-free radical under the experimental conditions. Ascorbic acid was taken as standard solution.

The paper described study of antibacterial and antioxidant properties of seed's methanol extracts of $A$. subulatum, collected from two different regions of Nepal.

The in vitro antimicrobial activities of Nepali black cardamoms collected from two different regions designated as Sample A and Sample B extracts against S. aureus, B. pumilus, E. coli, and S. enteric and their activity potentials were qualitatively assessed by the presence or absence of inhibition zones. The result of antimicrobial activity of Sample A and Sample B is presented in Table 1. The methanol extract of both samples had shown antimicrobial activities against the test microorganisms (the diameter of inhibition zone 10-14 mm). The results as given in Table 1 show that Sample B had greater potential as an antimicrobial agent against all the test microorganism than did Sample A extract. It was observed that both methanol seed extracts exhibited lesser inhibition on all test microorganisms in comparison with the standard antibacterial drug tetracycline. The result obtained here is in good correlation with the previously reported results as a wide variety of secondary metabolites such as tannins, alkaloids, and flavonoids having antimicrobial activities had been reported as the chemical constituents of $A$. subulatum. Kumar et al., and Kikuzaki et al. found the cardamom with antimicrobial activity and antioxidant action, respectively $[17,18]$. The antimicrobial nature of the cardamom extract is apparently related to the components reported in cardamom 1,8-cineole as the main component of essential oil of $A$. subulatum seed.

Antioxidants protect cells against damage caused by molecules known as free radicals. The antioxidant effects of plant extracts are mainly due to the presence of phenolic compounds such as flavonoids, phenolic acids, tannins, and phenolic diterpenes [17]. Numerous studies with plant phytochemicals showed that phytochemicals with antioxidant activity may reduce risk of cancer and improve the health. Methanolic extracts of A. subulatum (Sample A and Sample B) and standard ascorbic acid tested for in vitro antioxidant activity using the DPPH- assay method. The $\mathrm{IC}_{50}$ was calculated from the graph obtained by plotting the percentage scavenging against concentrations used (Fig. 1). The result is shown in Fig. 2. The scavenging effect of extracts and standard on the DPPH radical was found to be concentration dependent and was in the order of ascorbic acid>seed extracts. The Sample A and Sample B showed antioxidant activity with $\mathrm{IC}_{50}$ value of $7.7 \pm 2.0 \mu \mathrm{g} / \mathrm{mL}$, and $7.01 \pm 2.0 \mu \mathrm{g} / \mathrm{mL}$. The $\mathrm{IC}_{50}$ value for ascorbic acid was $3.8 \pm 0.14 \mu \mathrm{g} / \mathrm{mL}$. The result indicates that the antioxidant activity of Sample B was found

Table 1: Antibacterial activity of Sample A and Sample B of (i.e.,, methanol seed extract of black cardamom (Amomum subulatum Roxb.), tetracycline, and DMSO

\begin{tabular}{lllll}
\hline Plants & Name of microorganisms & \multicolumn{2}{l}{ Mean zone of inhibition $(\mathbf{m m}) *$} & \\
\cline { 3 - 5 } & & Plant extract $\mathbf{5 0}(\boldsymbol{\mu g} / \mathbf{w e l l})$ & Tetracycline 10 $(\boldsymbol{\mu g} / \mathbf{w e l l})$ & DMSO \\
\hline Sample A & B. pumilus & $11.5 \pm 0.15$ & $31.3 \pm 0.37$ & NA \\
& S. aureus & $10.4 \pm 0.35$ & $29.6 \pm 0.20$ & NA \\
& E. coli & $13.3 \pm 0.20$ & $26.6 \pm 0.20$ & NA \\
Sample B & S. enteric & $10.3 \pm 0.25$ & $31.1 \pm 0.10$ & NA \\
& B. pumilus & $12.3 \pm 0.20$ & $31.3 \pm 0.37$ & NA \\
& S. aureus & $14 \pm 0.5$ & $29.6 \pm 0.20$ & NA \\
& E. coli & $14.2 \pm 0.41$ & $26.6 \pm 0.20$ & NA \\
& S. enteric & $11 \pm 0.10$ & $31.1 \pm 0.10$ & NA \\
\hline
\end{tabular}

Results represent the means \pm SEM (standard error of mean) from at least three separate experiments, B. pumilus: Bacillus pumilus, S. enteric: Salmonella enteric,

S. aureus: Staphylococcus aureus, E. coli: Escherichia coli 


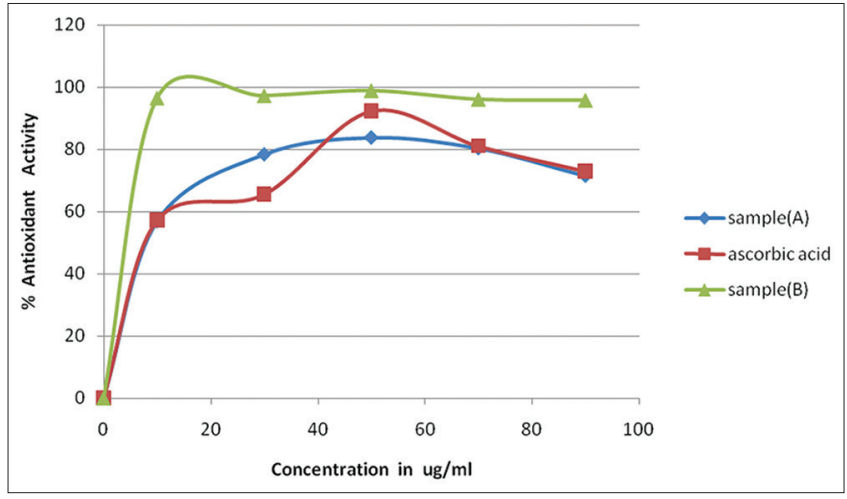

Fig. 1: Graph plot percentage inhibition against concentration showing 1, 1-diphenyl-2-picrylhydrazyl free radical scavenging activity of Sample A and Sample B compared with ascorbic acid. Results represent the means \pm standard error of mean from at least three separate

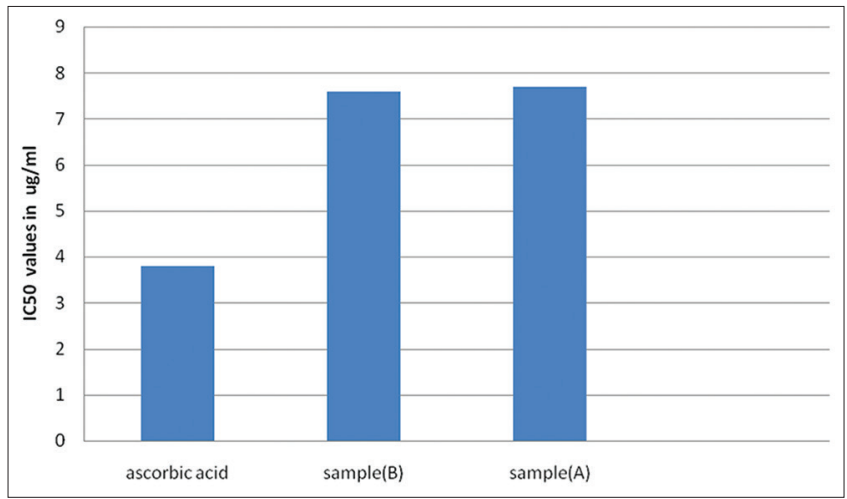

Fig. 2: The IC ${ }_{50}$ values of Sample A, Sample B, and ascorbic acid on 1-diphenyl-2-picrylhydrazyl

quit higher than Sample A whereas lesser than that of ascorbic acid. The result obtained here is well supported by the previous studied [17-21].

\section{CONCLUSION}

The preliminary results obtained from this study seem to justify the use of $A$. subulatum in dealing with different health disorders in terms of cost-effectiveness and easy of availability, especially for the people in remote area. Based on the comparison of the result obtained from the present study, it is concluded that the A. subulatum collected from Taplejung showed strong antibacterial and antioxidant activity than that of sample collected from the Panchthar (low altitude). The present study may provide a scientific support for the traditional use of this plant and may endow with the valuable idea for a complete study on the bioactive compound that contributes to these biological properties and also their possible mechanism of action are suggested.

\section{ACKNOWLEDGMENTS}

The authors are thankful to Universal Engineering College, Lalitpur, Nepal, for providing us laboratory for this research work. The authors also express their deep gratitude to Central Department of Microbiology, Tribhuvan University, Kirtipur, Nepal, providing microorganisms.

\section{REFERENCES}

1. Agaoglu S, Dostbil N, Alemdar S. Antimicrobial activity some spices in meat industry. Bull Vet Inst Pulawy 2007;81:53-57.

2. Ahmad I, Beg AZ. Antimicrobial and phytochemical studies on 45 Indian medicinal plants against multi-drug resistant human pathogens. J Ethnopharmacol 2001;74(2):113-23.

3. Arora DS, Kaur GJ. Antibacterial activity of some Indian medicinal plants. J Nat Med 2007;61(3):313-7.

4. Badei AZ, El-Akel AT, Faheid SM, Mahmound BS. Application of some spices in flavoring and preservation of cookies: 1-Antioxidant properties of cardamom, cinnamon and clove. Dtsch Lebensmitt Rundsch 2002;98:176-3.

5. Bentley R, Trimen H. Medicinal Plants. Vol. I-IV. London: J. \& A. Churchill; 1980.

6. Burt S. Essential oils: Their antibacterial properties and potential application in food-a review. Int J Food Microbiol 2004;94(3):223-53.

7. Burt SA, Reinders RD. Antibacterial activity of selected plant essential oils against Escherichia coli O157: H7. Lett Appl Microbiol 2003;36(3):162-7

8. Hinneburg I, Dorman DH, Hilunen R. Antioxidant activities of extracts from selected culinary herbs and spices. Food Chem 2006;97(1):122-9.

9. Hoque MM, Bari ML, Juneja VK, Kawamoto S. Antimicrobial activity of clove and cinnamon extracts, against food borne pathogens and spoilage bacteria, and inactivation of Listeria monocytogenes in ground meat with their essential oils. Rep Natl Food Res Inst 2008;72:9-3

10. Dixit A, Singh H, Sharma RA, Sharma A. Estimation of antioxidant and antibacterial activity of crude extracts of Thevetia peruviana (PERS.) K. SCHUM. Int J Pharm Pharm Sci 2015;7(2):55-9.

11. Anusuya N, Manian S. Antioxidant and free radical scavenging potential of different solvent extracts of Indigofera tinctoria L. Leaves. J Pharm Pharm Sci 2012;5(1):142-7.

12. Mikage M, Mouri C. Altitudinal variations of berberine content in the bank of Berberis plants from West Nepal. Newslett Himalayan Bot 2000;26:16-9.

13. Iwashina T, Omori Y, Kitajima J, Akiyama S, Suzuki T, Ohba H. Flavonoids in translucent bracts of the Himalayan Rheum nobile (Polygonaceae) as ultraviolet shields. J Plant Res 2004;117(2):101-7.

14. Dingle J, Reed WW, Solomons GI. The enzymatic degradation of pectin and other polysaccharide. II - Application of the 'Cup-plate' assay to the estimation of enzymes. J Sci Food Agric 1953;4:149-53.

15. Blois MS. Antioxidant determinations by the use of as table free radical. Nature 1958;181(4617):1199-200.

16. Brand-Williams W, Cuvelier ME, Berset C. Use of a free radical method to evaluate antioxidant activity. Food Sci Technol 1995;28(1):25-30

17. Kumar U, Kumar B, Bhandari A, Kumar Y. Phytochemical investigation and comparison of antimicrobial screening of clove and cardamom. Int J Pharm Sci Res 2010;1(12):138-47.

18. Kikuzaki H, Kawai Y, Nakatani N. 1,1-diphenyl-2-picrylhydrazyl radical-scavenging active compounds from greater cardamom (Amomum subulatum Roxb.). J Nutr Sci Vitaminol (Tokyo) 2001;47(2):167-71.

19. Chhetri H, Yogal NS, Serchan J, Anup KC, Mansoor S. Phytochemical and antimicrobial evaluations of some medicinal plants of Nepal. Kathmandu Univ J Sci Eng Technol 2008;1(5):49-54.

20. Kaskoos RA, Mir SR, Kapoor R, Ali M. Essential oil composition of fruit of Amomum subulatum Roxb. J Essent Oil Bearing Plants 2008;11:184-7.

21. Khattun M, Eguchis S, Yamaguchi T, Takamura H, Matoba T. Effect of thermal treatment of radical scavenging activity of some spices. Food Sci Technol Res 2006;12(3):178-85. 